\title{
HMGB1 regulates P-glycoprotein expression in status epilepticus rat brains via the RAGE/NF-кB signaling pathway
}

\author{
YUAN XIE, NIAN YU, YAN CHEN, KANG ZHANG, HAI-YAN MA and QING DI \\ Department of Neurology, Nanjing Brain Hospital Affiliated to Nanjing \\ Medical University, Nanjing, Jiangsu 210029, P.R. China
}

Received March 12, 2016; Accepted February 24, 2017

DOI: $10.3892 / \mathrm{mmr} .2017 .6772$

\begin{abstract}
Overexpression of P-glycoprotein (P-gp) in the brain is an important mechanism involved in drug-resistant epilepsy (DRE). High-mobility group box 1 (HMGB1), an inflammatory cytokine, significantly increases following seizures and may be involved in upregulation of P-gp. However, the underlying mechanisms remain elusive. The aim of the present study was to evaluate the role of HMGB1 and its downstream signaling components, receptor for advanced glycation end-product (RAGE) and nuclear factor- $\kappa \mathrm{B}(\mathrm{NF}-\kappa \mathrm{B})$, on P-gp expression in rat brains during status epilepticus (SE). Small interfering RNA (siRNA) was administered to rats prior to induction of SE by pilocarpine, to block transcription of the genes encoding HMGB1 and RAGE, respectively. An inhibitor of $\mathrm{NF}-\kappa \mathrm{B}$, pyrrolidinedithiocarbamic acid (PDTC), was utilized to inhibit activation of NF- $\kappa \mathrm{B}$. The expression levels of HMGB1, RAGE, phosphorylated-NF- $\kappa$ B p65 (p-p65) and P-gp were detected by western blotting. The relative mRNA expression levels of the genes encoding these proteins were measured using reverse transcription-quantitative polymerase chain reaction and the cellular localization of the proteins was determined by immunofluorescence. Pre-treatment with HMGB1 siRNA reduced the expression levels of RAGE, p-p65 and P-gp. PDTC reduced the expression levels of P-gp. These findings suggested that overexpression of P-gp during seizures may be regulated by HMGB1 via the RAGE/NF- $\mathrm{BB}$ signaling pathway, and may be a novel target for treating DRE.
\end{abstract}

Correspondence to: Professor Qing Di, Department of Neurology, Nanjing Brain Hospital Affiliated to Nanjing Medical University, 264 Guangzhou Road, Nanjing, Jiangsu 210009, P.R. China

E-mail: diqing@medmail.com.cn

Abbreviations: AED, anti-epilepsy drug; DRE, drug-refractory epilepsy; EP, pilocarpine-induced epilepsy; HMGB1, high-mobility

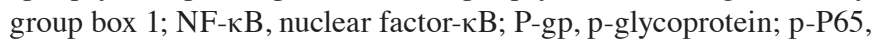
phospho-NF- $\kappa$ B p65; RAGE, receptor for advanced glycation end-product; siRNA, small interfering RNA

Key words: rat, status epilepticus, high-mobility group box 1, receptor for advanced glycation end-product, nuclear factor- $\kappa \mathrm{B}$, P-glycoprotein

\section{Introduction}

Epilepsy is the most common brain disorder affecting $>50$ million people worldwide (1). Despite advances in therapies for epilepsy, a third of patients with epilepsy are non-responsive or respond poorly to anti-epilepsy drugs (AEDs) and subsequently develop drug-resistant epilepsy (DRE) (2). There are a number of theories as to how this develops, including the involvement of P-glycoprotein (P-gp) overexpression, which is an efflux pump that is anchored at the blood-brain barrier $(3,4)$. This has been confirmed by brain tissues collected during surgery for DRE (5). P-gp is a multidrug resistance protein and is encoded by $M D R 1 A / B$ gene. It is primarily distributed at the luminal surface of capillary endothelial cells. However, P-gp can also be expressed in glial cells and neurons. Experiments have demonstrated that P-gp pumps out AEDs from neuronal cells to reduce the concentration of AEDs in brain tissue (6). Inhibiting P-gp expression may improve the efficacy of AEDs in DRE $(7,8)$. Therefore, $\mathrm{P}-\mathrm{gp}$ is postulated to be a novel clinical target for the treatment of multidrug refractory epilepsy (9). However, the exact underlying mechanisms of $\mathrm{P}$-gp overexpression and its regulatory pathways in DRE are not fully understood.

The immunity and inflammatory processes affecting P-gp expression in epilepsy have been established (10-12). Seizures may trigger multidimensional local inflammatory reactions in brain (13) that are involved in the generation and propagation of epileptic activity. High-mobility group box 1 (HMGB1), a ubiquitous chromatin component, is passively released by stressed or necrotic cells, and is overexpressed in epileptic brains. The interaction between HMGB1 and Toll-like receptor 4 (TLR4) stimulates the innate immune system and inflammation in tissues $(14,15)$. Our previous study demonstrated that P-gp may be downregulated by inhibition of TLR4 or HMGB1 during kainic acid (KA)-induced seizures in rat brains (16). Receptor for advanced glycation end-product (RAGE), another important ligand of HMGB1, has key role in innate immune activation and seizures (17). However, it is unknown whether RAGE activation contributes to the upregulation of $\mathrm{P}-\mathrm{gp}$ following seizures. Nuclear factor- $\kappa \mathrm{B}(\mathrm{NF}-\kappa \mathrm{B})$ is a downstream signaling molecule of RAGE, and is a ubiquitous transcription factor that serves a role in the regulation of immune response and inflammation (18). Our previous study suggested that silencing of inhibitor of $N F-\kappa B$ kinase subunit $\beta$ (IKK $\beta)$, which 
regulates the activity of $\mathrm{NF}-\kappa \mathrm{B}$, reduced the expression levels of P-gp and reduced seizures (19). HMGB1 binds to RAGE to stimulate the biological effects of NF- $\kappa$ B. RAGE/NF- $\kappa$ B is known to be a regulator of inflammation $(20,21)$. The present study investigated whether HMGB1 binds to RAGE, leading to activation of $\mathrm{NF}-\kappa \mathrm{B}$ and enhanced transcription of $M D R 1 A / B$ and $\mathrm{P}$-gp expression during brain seizures. The results of the present study may provide a molecular mechanism and a novel target for the treatment of DRE.

\section{Materials and methods}

Animals. Male Sprague-Dawley (SD) rats (age, 6-7 weeks; weight, 200-250 g) were purchased from Shanghai SLAC Laboratory Animal Co., Ltd. (Shanghai, China) and were housed under controlled standard conditions at $65 \pm 5 \%$ humidity and $21 \pm 2^{\circ} \mathrm{C}$, a $12 \mathrm{~h}$ light/dark cycle and with food and water available. The rats were housed under these conditions for one week prior to treatment. Experimental procedures were approved by the Animal Ethics Committee of Nanjing Medical University, according to international standards.

Experimental groups. Animals were divided randomly into 6 groups: Sham group (treated with saline as a control, $n=21$ ); EP group (treated with pilocarpine; $n=78$ ); small interfering RNA (siRNA) group (treated with pilocarpine plus siRNA; $\mathrm{n}=24$ ); pyrrolidinedithiocarbamic acid (PDTC) group (treated only with PDTC; $n=12$ ); EP + PDTC group (treated with pilocarpine plus PDTC; $n=12$ ); scrambled group (treated with pilocarpine plus scrambled siRNA; $n=4)$.

Surgery for intracerebroventricular (ICV) injection. The purpose of the operation was to inject siRNA. SD rats were anesthetized with $10 \%$ chloral hydrate $(3 \mathrm{ml} / \mathrm{kg})$ and placed on stereotactic apparatus. A stainless steel single guide cannula (PlasticsOne Inc., Roanoke, VA, USA) was implanted into the right lateral ventricle with coordinates of $0.8 \mathrm{~mm}$ posterior to the bregma, $1.5 \mathrm{~mm}$ lateral to the midline and $4.5 \mathrm{~mm}$ depth to the surface of the skull (22). The cannula was fixed with dental cement (Heraeus Kulzer $\mathrm{GmbH}$, Wehrheim, Germany).

Pilocarpine-induced status epilepticus (SE). Rats were administrated with lithium chloride (127 mg/kg; Sigma-Aldrich; Merck KGaA, Darmstadt, Germany) by intraperitoneal (IP) injection $24 \mathrm{~h}$ before pilocarpine treatment. Methyl scopolamine (1 mg/kg, IP; Sigma-Aldrich) was delivered $30 \mathrm{~min}$ before pilocarpine to reduce the peripheral effects and to enhance survival. A single dose of pilocarpine $(30 \mathrm{mg} / \mathrm{kg}$, IP) (Sigma-Aldrich) was administered. Subsequently, rats received repeated injections of pilocarpine $(10 \mathrm{mg} / \mathrm{kg}$, IP) every $30 \mathrm{~min}$ until they developed convulsive seizures. The maximum number of pilocarpine injections was 5 per animal (23). Diazepam (10 mg/kg; Sigma-Aldrich) was utilized to terminate seizure activity $90 \mathrm{~min}$ after the onset of SE. Severity of the convulsions were evaluated by Racine's classification and denoted the following stages: 0 , behavioral arrest; 1 , face clonus; 2 , head nodding; 3 , forelimb clonus; 4 , forelimb clonus and rearing, 5, forelimb clonus with rearing and falling (24). Animals classified as less than Racine's stage 4 were excluded from the experiment. The sham groups were injected with normal saline instead of pilocarpine.

siRNA micro-injection and PDTC administration. siRNAs targeting $H M G B 1$ and RAGE $m R N A$ were designed and synthesized by Shanghai GenePhama Co., Ltd. (Shanghai, China). siRNA sequences are listed in Table I. As described previously, the rats of the siRNA group were treated with $10 \mu \mathrm{l}$ siRNA $(5 \mu \mathrm{mol} / \mathrm{l})(25)$ by a microinjection pump via a pre-implanted cannula 30 min prior to pilocarpine injection. Following each injection, the needle was left in place for $5 \mathrm{~min}$ to allow for drug diffusion. The sham group was treated with $10 \mu 1$ saline. The Scrambled group was administrated with $10 \mu \mathrm{l}$ scrambled siRNA $(5 \mu \mathrm{mol} / \mathrm{l})$ and served as the negative control.

Rats in the EP + PDTC group were treated with PDTC (100 mg/kg, IP; BioVision, Inc., Milpitas, CA, USA) at $14.5 \mathrm{~h}$ and $15 \mathrm{~min}$ prior to the first pilocarpine injection and at 90 min after onset of SE. A further two injections of PDTC at the same dose was administrated $5 \mathrm{~h}$ after termination of $\mathrm{SE}$ and $23.5 \mathrm{~h}$ after the first injection of pilocarpine (26). The sham group was treated with the same volume of saline and the PDTC group was treated IP with $100 \mathrm{mg} / \mathrm{kg}$ PDTC alone.

Reverse transcription-quantitative polymerase chain reaction $(R T-q P C R)$. Total RNA was extracted from the hippocampus of the rats using TRIzol reagent (Invitrogen; Thermo Fisher Scientific, Inc., Waltham, MA, USA) according to the manufacturer's protocol. The concentration and purity of the RNA was measured spectrophotometrically at 260 and $280 \mathrm{~nm}$. Total RNA (500 ng) was subjected to DNase I digestion (Takara Bio, Inc., Otsu, Japan), and was subsequently utilized for cDNA synthesis using the PrimeScript ${ }^{\mathrm{TM}}$ RT Master Mix (Takara Bio, Inc.). qPCR was then performed using the SYBR ${ }^{\circledR}$ Premix Ex Taq ${ }^{\mathrm{TM}}$ kit (Takara Bio, Inc.) with $1 \mu \mathrm{l} 0.5 \mu \mathrm{M}$ forward and reverse primers (final concentration, $0.5 \mu \mathrm{m}$; Sangon Biotech Co., Ltd., Shanghai, China; Table II) and $8 \mu$ l diluted cDNA on a 7300 Real-Time PCR System (Applied Biosystems; Thermo Fisher Scientific, Inc.). Cycling conditions were as follows: Initial predenaturation step at $95^{\circ} \mathrm{C}$ for $30 \mathrm{sec}$, followed by 40 cycles of denaturation at $95^{\circ} \mathrm{C}$ for $5 \mathrm{sec}$ and annealing at $60^{\circ} \mathrm{C}$ for $31 \mathrm{sec}$. The relative mRNA expression of the target gene was normalized to $G A P D H$ and was calculated using the $2^{-\Delta \Delta \mathrm{Cq}}$ method (27)

Western blot analysis. Total protein was extracted from the hippocampus of rats using a protein extraction kit (Nanjing KeyGen Biotech Co., Ltd., Nanjing, China). Samples were homogenized and centrifuged at $14,000 \times \mathrm{g}$ for $15 \mathrm{~min}$, and the supernatant was harvested and diluted to $6.7 \mu \mathrm{g} / \mu \mathrm{l}$ in SDS/bromophenol blue loading buffer, prior to heating for $5 \mathrm{~min}$ at $100^{\circ} \mathrm{C}$. Samples were loaded onto $10 \%$ gels, separated by SDS-PAGE and transferred onto polyvinylidene difluoride membranes (EMD Millipore, Billerica, MA, USA). Membranes were blocked in $5 \%$ bovine serum albumin (Sigma-Aldrich; Merck KGaA) at room temperature for $2 \mathrm{~h}$ and subsequently incubated at $4^{\circ} \mathrm{C}$ overnight with the following primary antibodies: Rabbit anti-HMGB1 (1:1,000; catalog no. ab18256; Abcam, Cambridge, UK); rabbit anti-RAGE (1:1,000; catalog no. ab3611; Abcam); mouse 
Table I. siRNA sequences.

SiRNA Sequence (5'-3')

\section{HMGB1-F \\ HMGB1-R \\ RAGE-F \\ RAGE-R}

Negative control-F

Negative control-R
GGAAGACGAAGAUGAAGAATT UUCUUCAUCUUCGUCUUCCTT GCCGGAAAUUGUGAAUCCUTT AGGAUUCACAAUUUCCGGCTT UUCUCCGAACGUGUCACGUTT ACGUGACACGUUCGGAGAATT

siRNA, small interfering RNA; F, forward; R, reverse; bp, base pair; $H M G B 1$, high-mobility group box 1 gene; $R A G E$, receptor for advanced glycation end-product.

anti-P-gp (1:50, catalog no. 517310; Calbiochem; EMD Millipore); rabbit anti-phosphorylated-NF- $\kappa$ B p65 (p-p65) (1:1,000, catalog no. 3033; Cell Signaling Technology, Inc., Danvers, MA, USA). Following incubation with horseradish peroxidase-conjugated goat anti-rabbit secondary antibodies (1:5,000; catalog no. ZB230; ZSGB-BIO, Beijing, China) or anti-mouse secondary antibodies (1:5,000; catalog no. ZB2305; ZSGB-BIO) for $1.5 \mathrm{~h}$ at room temperature, proteins were detected using electrochemiluminescence (catalog no. WBKLS0500; EMD Millipore) according to the manufacturer's instructions, with Quantity One software (version 4.62; Bio-Rad Laboratories, Inc., Hercules, CA, USA). The optical density of each sample was measured using Scion Image software (version 1.47; Scion Corporation, Frederick, MD, USA). The optical density of each sample was normalized to the mouse anti- $\beta$-actin (1:500; catalog no. BM0627; Wuhan Boster Biological Technology, Ltd., Wuhan, China) loading control.

Immunofluorescence. Rat brains were fixed in $4 \%$ paraformaldehyde following trans-cardiac perfusion overnight at $4^{\circ} \mathrm{C}$, and subsequently soaked in 20 and $30 \%$ sucrose for 2 to 3 days, respectively. The brains were then embedded into optimal cutting temperature compound (catalog no. C1400; Applygen Technologies, Inc., Beijing, China). Sections (8- $\mu \mathrm{m}$ thick) were prepared using a vibrating slicer and staining was performed using a standard procedure (28). Briefly, sections were blocked in $0.01 \mathrm{~mol} / 1$ serum (either rabbit or mouse according to the secondary antibody used; Wuhan Boster Biological Technology, Ltd.) at room temperature for $2 \mathrm{~h}$. The redundant serum was removed then sections were incubated with the following primary antibodies: Rabbit anti-HMGB1 (1:500; catalog no. ab18256; Abcam), rabbit anti-RAGE (1:200; catalog no. ab3611; Abcam) and mouse anti-P-gp (1:50; catalog no. 517310; EMD Millipore) at $4^{\circ} \mathrm{C}$ overnight. Goat anti-rabbit FITC-conjugated IgG (1:1,000 PBS dilution; catalog no. BA1105; Wuhan Boster Biological Technology, Ltd.) or goat anti-mouse cyanine 3-conjugated IgG (1:1,000 PBS dilution; catalog no. BA1101; Wuhan Boster Biological Technology, Ltd.) secondary antibodies were added at room temperature for $1 \mathrm{~h}$, followed by DAPI (catalog no. AR1177; Wuhan Boster Biological Technology, Ltd.) nuclear stain. Sections were visualized using a Leica fluorescence microscope (DM4000; Leica
Microsystems GmbH, Wetzlar, Germany) and the Leica QWin version 3 software (Leica Microsystems $\mathrm{GmbH}$ ) was used for analysis. Different cell types were identified by analyzing cell morphology.

Statistical analysis. Data was analyzed using SPSS software version 13.0 (SPSS, Inc., Chicago, IL, USA) and are presented as the mean \pm standard deviation. Significant differences were analyzed using a one-tailed Student's t-test, or by one-way analysis of variance followed by the Least Significant Difference post-hoc test for multiple comparisons. $\mathrm{P}<0.05$ was considered to indicate a statistically significant difference.

\section{Results}

Seizure behavior. The concentration of pilocarpine $(35.50 \pm 9.12 \mathrm{mg} / \mathrm{kg})$ utilized for inducing seizures was equal to that of previous experiments (26). Following pilocarpine administration, hypersalivation, piloerection, licking, chromodacryorrhea, swallowing and chewing occurred immediately. Subsequently, clonic movements of forelimbs, head bobbing and motor limbic seizures were observed. The average latency of first seizures (29) and from first pilocarpine injection to SE were $35.02 \pm 24.43$ and $37.93 \pm 24.78 \mathrm{~min}$, respectively. Induction success refers to the percentage of rats who had seizures, however, the level of which may not be suitable for further experiments; this also includes rats who had seizures however, they succumbed within $90 \mathrm{~min}$ following SE. Model success refers to the percentage of rats whose seizure level reached the experimental requirements; these rats survived the $90 \mathrm{~min}$ period following SE. The rates of induction and model success in rats in the present study were 91.28 and $82.05 \%$, respectively. The rate of failure, the percentage of rats that were not model successful, was $8.21 \%$ and the rate of total mortality, which included anesthesia-associated mortality, rats succumbing during the induction of SE and mortality prior to the scheduled time of specimen collection, was $18.46 \%$.

Expression of HMGB1, RAGE, p-p65 and P-gp following SE. At $6,12,24,48$ and $72 \mathrm{~h}$, and 5 and 7 days post-termination of seizures, HMGB1, RAGE, p-p65 and P-gp were measured in the hippocampus of rat brains by western blotting. Compared with the Sham group, the expression levels of HMGB1 were significantly enhanced following $48 \mathrm{~h}(\mathrm{P}<0.05), 72 \mathrm{~h}$ $(\mathrm{P}<0.0001)$ and 5 days $(\mathrm{P}<0.01) \mathrm{SE}$ termination, as were the expression levels of RAGE $(\mathrm{P}<0.01$ and $\mathrm{P}<0.05)$ and $\mathrm{P}-\mathrm{gp}$ $(\mathrm{P}<0.05$ and $\mathrm{P}<0.0001)$ at $72 \mathrm{~h}$ and 5 days respectively, and p-p65 was significantly enhanced following $72 \mathrm{~h}(\mathrm{P}<0.01$; Fig. 1). However, the expression levels of HMGB1 were reduced at $24 \mathrm{~h}$ and 7 days compared with $12 \mathrm{~h}$ and 5 days SE termination, respectively $(\mathrm{P}<0.05$; Fig. 1$)$. The expression levels of RAGE $(\mathrm{P}<0.05)$ and p-p65 $(\mathrm{P}<0.01)$ were reduced following 7 days compared with $72 \mathrm{~h}$, as were the expression levels of p-p65 and P-gp at 7 days compared with 5 days termination ( $\mathrm{P}<0.05$; Fig. 1). The greatest expression of HMGB1, RAGE and p-p65 was observed at $72 \mathrm{~h}$, and declined at later time points (Fig. 1). However, expression levels of P-gp continued to increase at 5 days, which were subsequently reduced by 7 days (Fig. 1). 
Table II. Primers used for reverse transcription-quantitative polymerase chain reaction.

\begin{tabular}{llc}
\hline Primer & \multicolumn{1}{c}{ Sequence $\left(5^{\prime}-3^{\prime}\right)$} & Product size (bp) \\
\hline HMGB1-F & CTGATGCAGCTTATACGAAG & 20 \\
HMGB1-R & TCAGGTAAGGAGCAGAACAT & 20 \\
RAGE-F & GAATCCTCCCCAATGGTTCA & 20 \\
RAGE-R & GCCCGACACCGGAAAGT & 17 \\
MDR1A-F & GAGTGAAAAGGTCGTCCAGGAAGCG & 25 \\
MDR1A-R & TCTCGCATGGTCACAGTTCATGAGC & 25 \\
MDR1B-F & CCCAAAGTGACACTGGTGCCTCTG & 24 \\
MDR1B-R & GCCTGGAGCCCATAGCCCCTTTA & 24 \\
GAPDH-F & ATGACTCTACCCACGGCAAG & 20 \\
GAPDH-R & TACTCAGCACCAGCATCACC & 20 \\
\hline
\end{tabular}

F, forward; R, reverse; bp, base pair; HMGB1, high-mobility group box 1 gene; RAGE, receptor for advanced glycation end-product gene; MDR1A and MDR1B, P-glycoprotein gene.
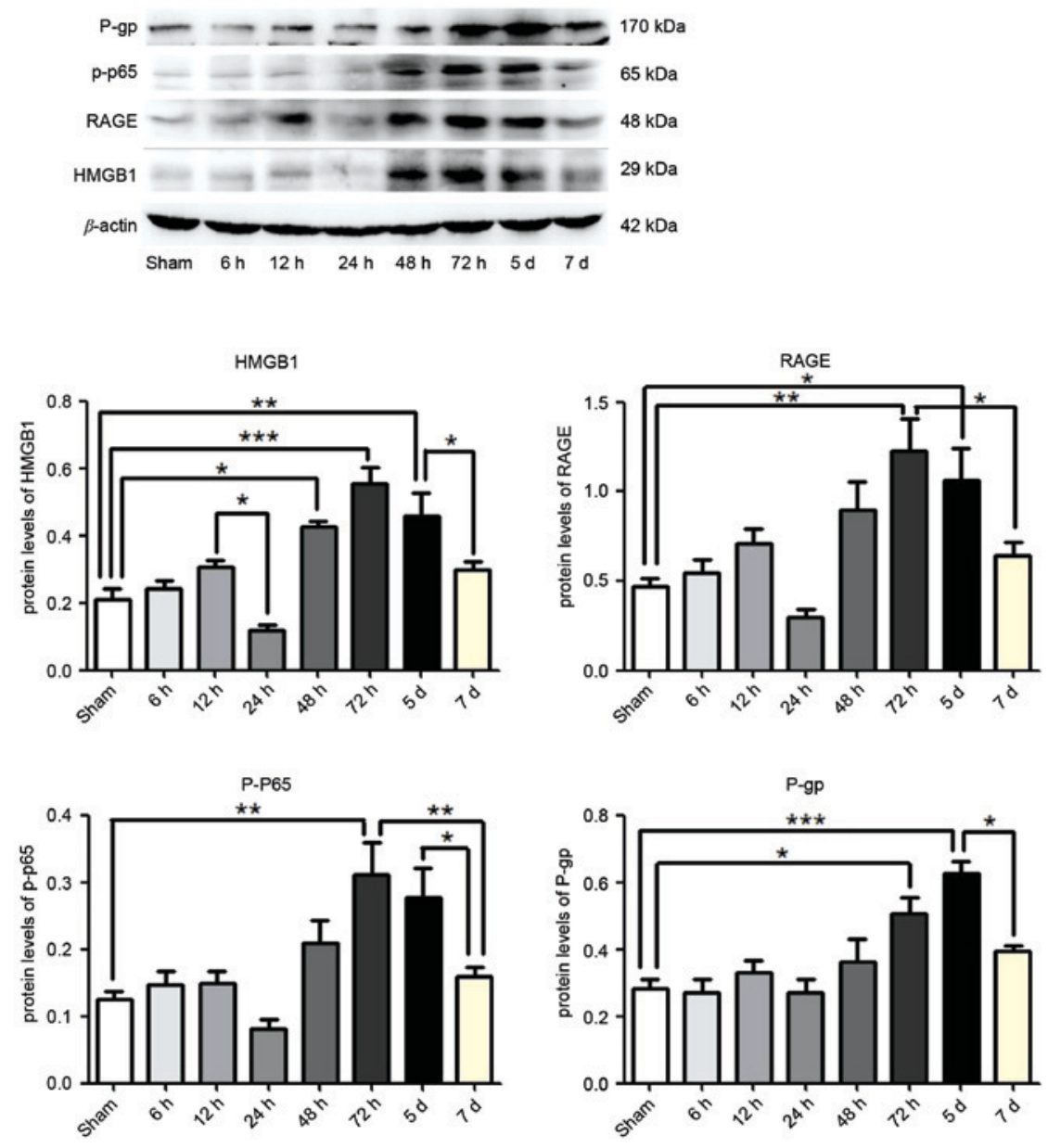

Figure 1. Protein expression levels of HMGB1, p-p65, RAGE and P-gp in the hippocampus following status epilepticus. Proteins were measured at 6, 12, 24, $48,72 \mathrm{~h}, 5$ and 7 days after termination of seizures, by western blotting. $\beta$-actin served as the loading control. Densitometry analysis was performed and data are presented as mean \pm standard deviation. ${ }^{*} \mathrm{P}<0.05,{ }^{* *} \mathrm{P}<0.01$ and ${ }^{* * *} \mathrm{P}<0.0001$. HMGB1, high-mobility group box 1; RAGE, receptor for advanced glycation end-product; p-p65, phosphorylated-NF-кB p65; P-gp, P-glycoprotein.

HMGB1 siRNA pre-treatment inhibits seizure-induced overexpression of p-p65, RAGE and P-gp. At $30 \mathrm{~min}$ prior to IP pilocarpine treatment, HMGB1 siRNA was administered to rats (ICV injection). At 3 days after SE termination, HMGB1, RAGE, p-p65 and P-gp expression levels were measured by western blotting. Protein levels of HMGB1 $(\mathrm{P}<0.01)$, 
RAGE $(\mathrm{P}<0.01)$, P-gp $(\mathrm{P}<0.01)$ and p-p65 $(\mathrm{P}<0.0001)$ in the EP group were significantly greater compared with expression in the sham group (Fig. 2A). Pre-treatment with HMGB1 siRNA significantly reduced the expression levels of all proteins compared with the EP and scrambled groups $(\mathrm{P}<0.01)$. The mRNA expression levels of $H M G B 1, R A G E$, $M D R 1 A$ and $M D R 1 B$ supported the western blotting data (Fig. 2B). Immunofluorescence staining of tissue sections demonstrated that HMGB1 was localized to the nuclei and cytoplasm of neurons (Fig. 2C). P-gp was primarily localized to blood vessels. HMGB1 and P-gp were expressed in low levels in the Sham group; however, a greater number of cells expressed HMGB1 and P-gp in the hippocampal CA3 region of the EP group. Compared with the EP group, the number of cells expressing HMGB1 and $\mathrm{P}-\mathrm{gp}$ was reduced in the group treated with HMGB1 siRNA (Fig. 2C).

RAGE knockdown attenuates seizure-induced upregulation of p-p65 and P-gp. Protein expression levels of RAGE, p-p65 and $\mathrm{P}$-gp were significantly reduced in the siRNA group compared with the EP and scrambled group ( $\mathrm{P}<0.01$; Fig. 3A). Similarly, in the group treated with $R A G E$ siRNA, mRNA expression of $R A G E, M D R 1 A$ and $M D R 1 B$ were significantly reduced compared with the EP and scrambled groups (Fig. 3B). Immunofluorescence staining demonstrated that RAGE and P-gp were upregulated in the EP group compared with the sham group. Pre-treatment with $R A G E$ siRNA resulted in reduced numbers of P-gp positive cells compared with the scrambled group (Fig. 3C).

Blocking $N F-\kappa B$ activity using PDTC reduces $P$-gp expression in rat brains following seizures. To determine whether $\mathrm{NF}-\kappa \mathrm{B}$ may regulate the expression of P-gp, PDTC, a specific inhibitor of $\mathrm{NF}-\kappa \mathrm{B}$ was utilized. As demonstrated in Fig. 4A, $72 \mathrm{~h}$ after SE termination, the protein expression levels of $\mathrm{P}-\mathrm{gp}$ in the EP + PDTC group were significantly reduced compared with the EP group $(\mathrm{P}<0.01)$. This was supported by the mRNA expression levels of $M D R 1 A / B$ (Fig. 4B), and the immunofluorescence staining of P-gp (Fig. 4C).

\section{Discussion}

The possibility that inflammatory processes in the brain contribute to seizures and the establishment of a chronic epileptic foci, is becoming increasingly recognized. Pro-inflammatory cytokines, including interleukin-1 $\beta$, and danger signals, including HMGB1 and S100 $\beta$, are overexpressed in human and experimental epileptogenic tissues (30-32). They have proconvulsant activity in various seizure models, possibly by reducing the seizure threshold via functional interactions with classical neurotransmitter systems (33). This demonstrates potential novel targets for therapeutic intervention to epilepsy.

HMGB1 is a nuclear protein that has cytokine-like functions following its extracellular release. It is either passively released from cells undergoing injury or actively secreted by cells under stressful conditions (34). The hyperacetylated form of HMGB1 regulates the transcription of various pro-inflammatory cytokines via binding to TLR4 and RAGE $(35,36)$.
Experimental models of epilepsy suggest that HMGB1-TLR4 signaling may contribute to seizures in humans, and could potentially be targeted to produce anticonvulsant effects in patients currently resistant to drugs (14). In addition, our previous study demonstrated that the susceptibility to seizures may be reduced by inhibition of HMGB1 and TRL4 in KA-induced epilepsy (37).

The present study revealed that the expression levels of HMGB1 were enhanced following SE up to $72 \mathrm{~h}$, which were subsequently reduced again. However, there was a marked decrease in HMGB1 expression at $24 \mathrm{~h}$. Luo et al (38) reported a similar effect in a KA-induced seizure mouse model. Wang et al (39) revealed that HMGB1 was released by macrophages $12 \mathrm{~h}$ post-stimulation and this resulted in an intracellular decrease in HMGB1 stores. In addition, HMGB1 secretion was reduced $24 \mathrm{~h}$ post-stimulation and resynthesized. It was speculated that brain cells may have similar mechanisms. Proliferated neuroglia cells were demonstrated to be involved in enhanced secretion of HMGB1 24 h post-stimulation (39).

RAGE is a transmembrane receptor of the immunoglobulin superfamily and interacts with ligands following activation of pro-inflammatory and immune responses (40). A previous study suggested that overexpression of RAGE in temporal epilepsy contributes to hyperexcitability in acute and chronic seizures. A potential underlying mechanism may be that HMGB1 activates RAGE, resulting in inflammation in epileptic brains (17).

It is established that HMGB1/RAGE have a role in inflammatory responses $(41,42)$, and their interaction results in downstream activation of the pro-inflammatory transcription factor, $N F-\kappa B(43) . N F-\kappa B$ is a key protein that is regulated by RAGE signaling (44). Upon activation, $N F-\kappa B$ translocates to the nucleus and subsequently binds to DNA sequences to stimulate transcription of target genes, including various cytokines, adhesion molecules and the gene encoding RAGE itself (45). In present study, $\mathrm{NF}-\kappa \mathrm{B}$ expression levels were reduced following knockdown of HMGB1 and RAGE, which suggested that HMGB1/RAGE regulates the transcription of the gene encoding NF- $\mathrm{KB}$.

Our previous study demonstrated that following knockdown of the gene encoding IKK $\beta$, which phosphorylates an inhibitory protein of $\mathrm{NF}-\kappa \mathrm{B}$ to enable its nuclear migration, expression of the $\mathrm{P}$-gp protein was reduced in a KA-induced epileptic brain. This result concurred with the present study, as inhibition of NF- $\kappa$ B by PDTC following SE termination resulted in reduced expression levels of $\mathrm{P}-\mathrm{gp}$. Therefore, it is possible that $\mathrm{NF}-\kappa \mathrm{B}$ regulates $M D R 1 A / B$ gene transcription.

In rodents, $\mathrm{P}-\mathrm{gp}$ is encoded by the $M D R 1 A$ and $M D R 1 B$ genes. P-gp encoded by $M D R 1 A$ serves a role as an efflux pump in cells of the liver, intestine, kidney and blood-brain barrier (46). The mRNA expression levels of $M D R I A$ and $M D R 1 B$ in the present study were not significantly different. In addition to vascular endothelial cells, nerve cells can express P-gp in the brain following seizures (47). However, the immunofluorescence staining in the present study demonstrated that P-gp was primarily localized to blood vessels, and there was little expression observed in neurons. This may be due to the model utilized and the time in which specimens were observed. van Vliet et al (48) demonstrated that P-gp is observed in 

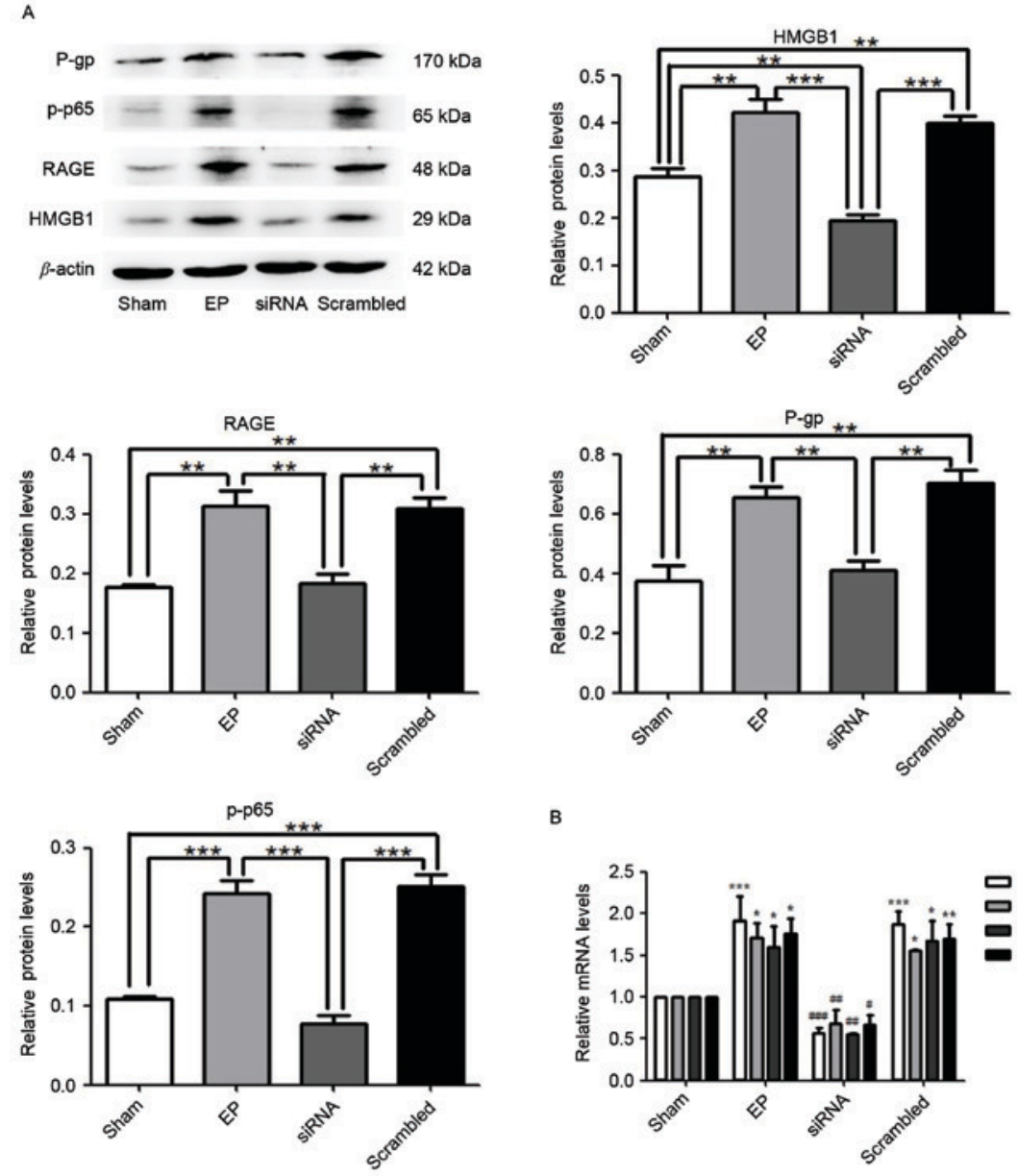

B
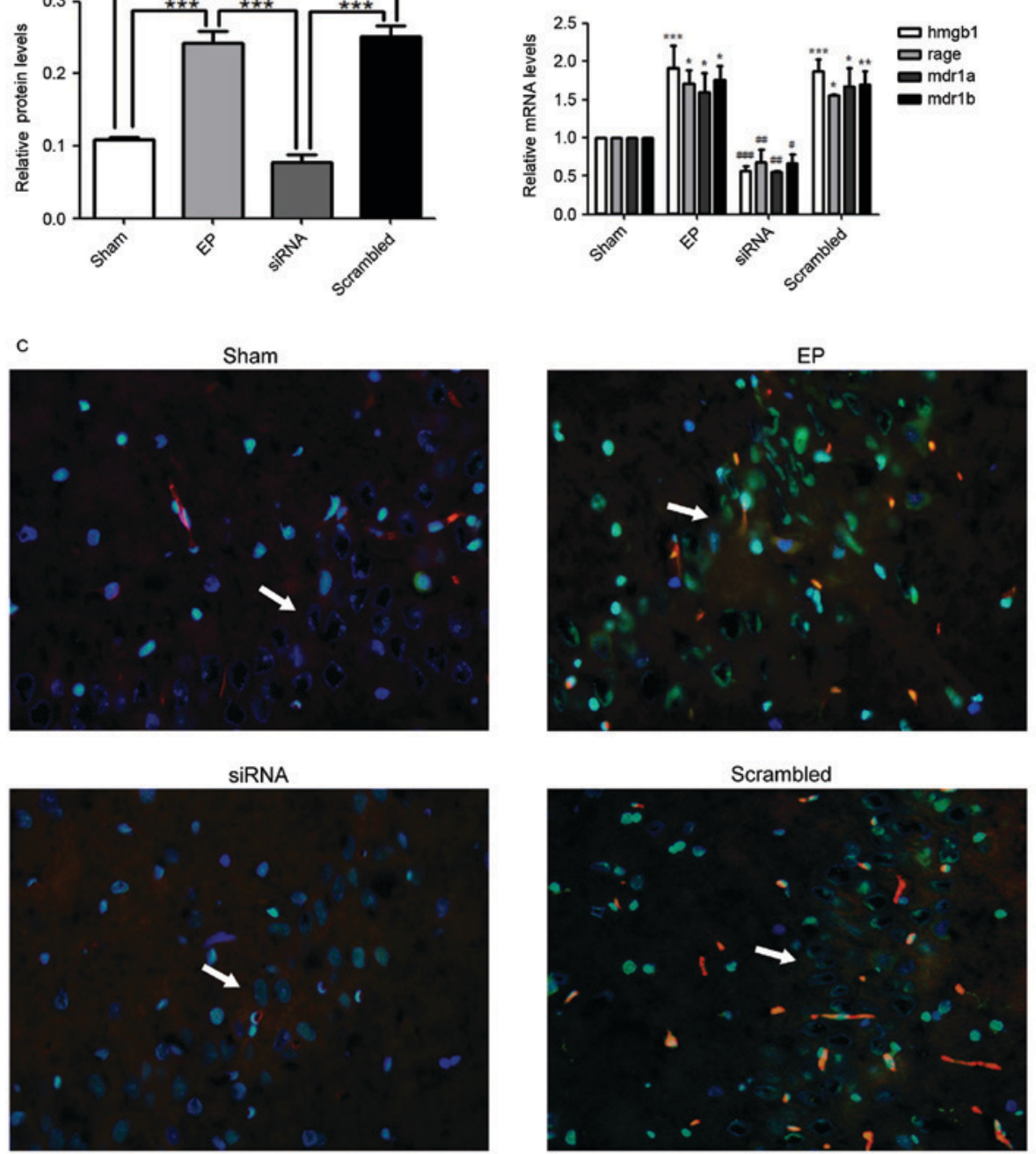

Figure 2. $H M G B 1$ siRNA reduces the expression levels of RAGE, p-p65 and P-gp. (A) Protein samples were analyzed $72 \mathrm{~h}$ following status epilepticus termination. Densitometry analysis was performed and data are presented as mean \pm standard deviation. ${ }^{*} \mathrm{P}<0.05,{ }^{* *} \mathrm{P}<0.01,{ }^{* * *} \mathrm{P}<0.0001$. (B) HMGB1, RAGE and MDR1A and MDR1B mRNA expression levels were significantly reduced following treatment with HMGB1 siRNA. "P $<0.05,{ }^{* *} \mathrm{P}<0.01$ and ${ }^{* * *} \mathrm{P}<0.0001$ vs. Sham; ${ }^{\#} \mathrm{P}<0.05,{ }^{\# \#} \mathrm{P}<0.01$ and ${ }^{\# \# \#} \mathrm{P}<0.0001$ vs. EP. (C) The localization of HMGB1 and $\mathrm{P}$-gp in the hippocampal CA3 region (indicated by white arrows) of rat brains, as determined by immunofluorescence staining. Blue=nuclei, green=HMGB1 and red=P-gp. Images were captured using $\times 400$ magnification. HMGB1 and P-gp were significantly reduced in the siRNA group compared with the EP and scrambled groups. HMGB1 was localized to the nuclei and cytoplasm. P-gp was primarily localized to blood vessels. P-gp, P-glycoprotein; p-p65, phosphorylated-NF-кB p65; RAGE, receptor for advanced glycation end-product; HMGB1, high-mobility group box 1 gene; MDR1A and MDR1B, P-glycoprotein genes; EP, pilocarpine-induced epilepsy group. 
A
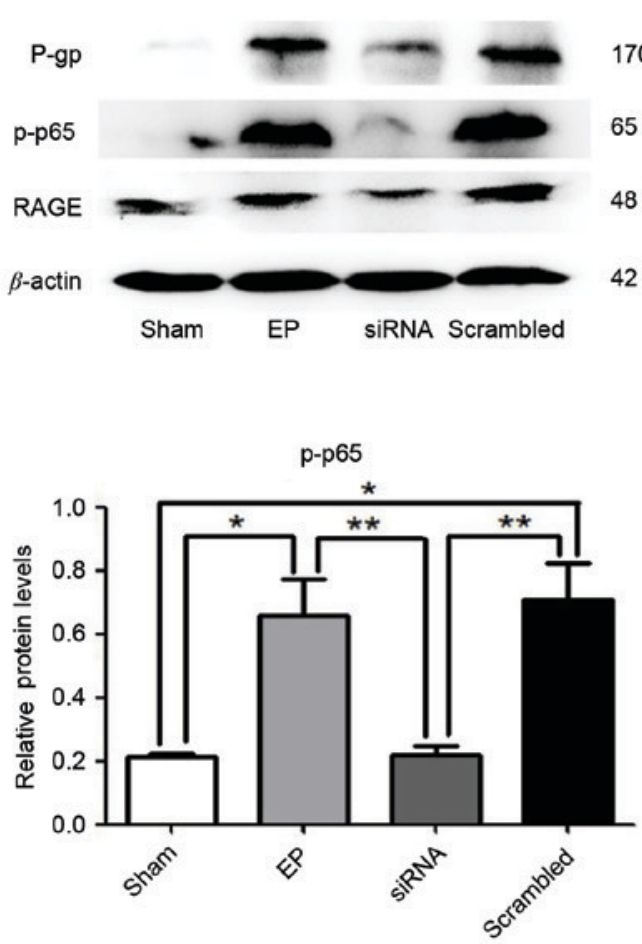

B
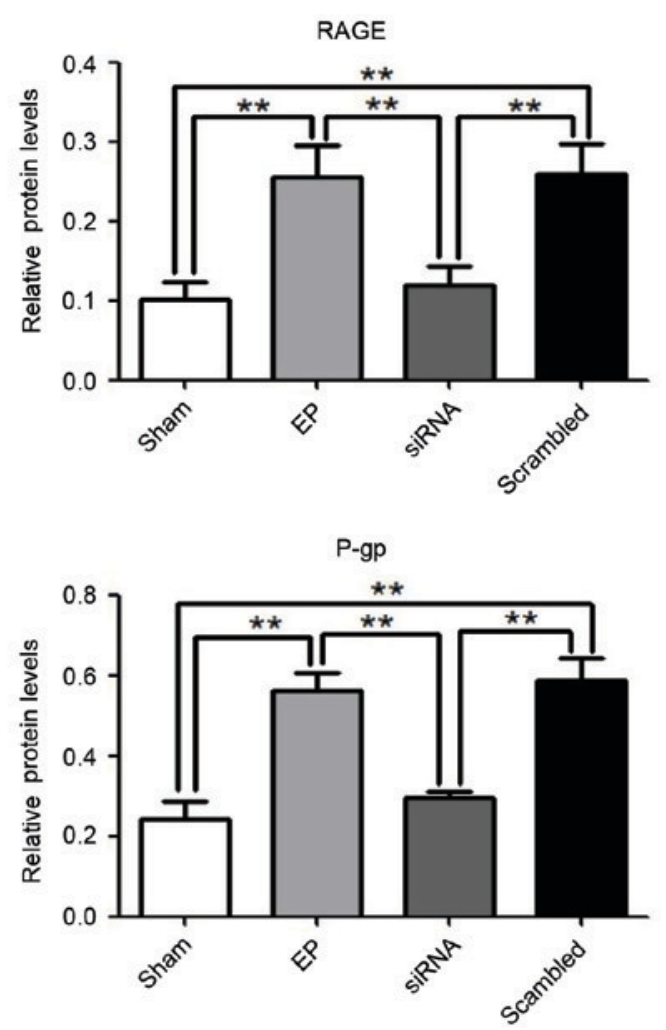

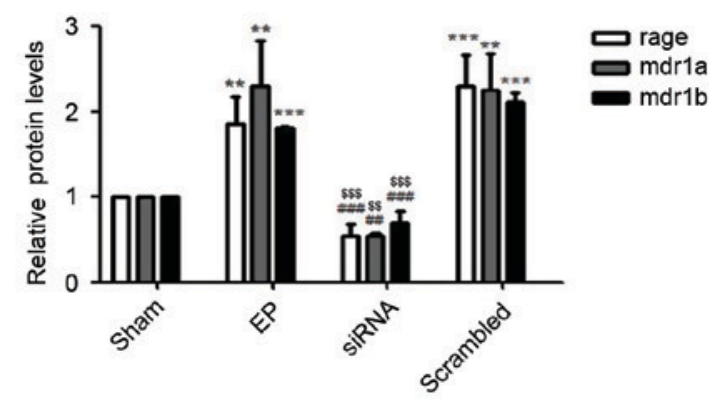

C
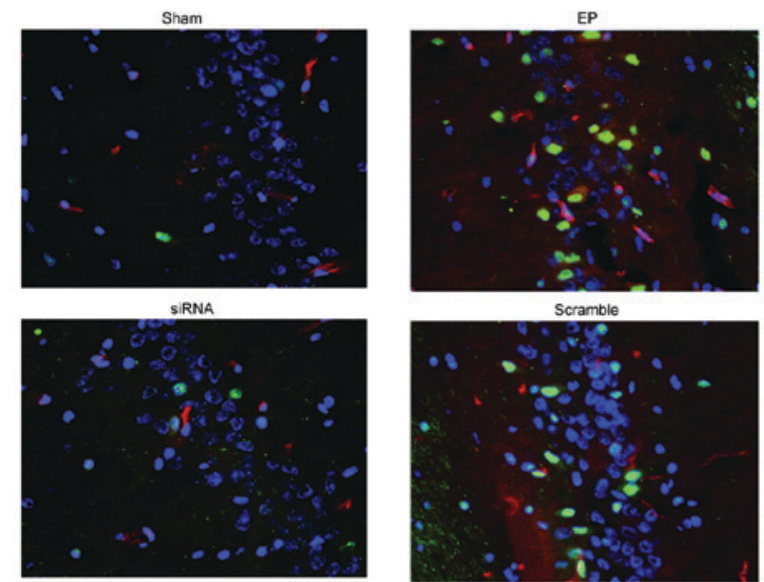

Figure 3. RAGE knockdown reduces seizure-induced p-p65 and P-gp overexpression. Specimens were collected $72 \mathrm{~h}$ following status epilepticus termination. (A) RAGE, p-p65 and P-gp were significantly reduced in the siRNA group compared with the EP and scrambled groups, as determined by western blotting. Densitometry analysis was performed and data are presented as the mean \pm standard deviation. ${ }^{*} \mathrm{P}<0.05$ and ${ }^{* *} \mathrm{P}<0.01$. (B) mRNA expression levels of $R A G E$ and $M D R 1 A / B$ in the siRNA group were significantly reduced compared with the EP and Scrambled group. ${ }^{* *} \mathrm{P}<0.01$ and ${ }^{* * * *} \mathrm{P}<0.0001 \mathrm{vs}$. sham; ${ }^{\# \#} \mathrm{P}<0.01$ and

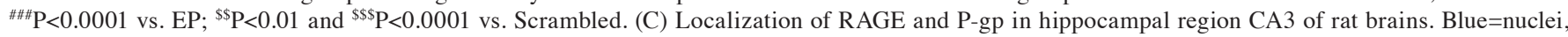
green=RAGE and red=P-gp. Images were captured using $\mathrm{x} 400$ magnification. Compared with the EP and scramble groups, the expression levels of RAGE and P-gp in the siRNA group were significantly reduced. RAGE was primarily localized to the nuclei of neurons and P-gp was primarily localized to blood vessels. RAGE, receptor for advanced glycation end-product; p-p65, phosphorylated-NF-кB p65; P-gp, P-glycoprotein; MDR1A and MDR1B, P-glycoprotein gene; RAGE, receptor for advanced glycation end-product; EP, pilocarpine-induced epilepsy group. 
A
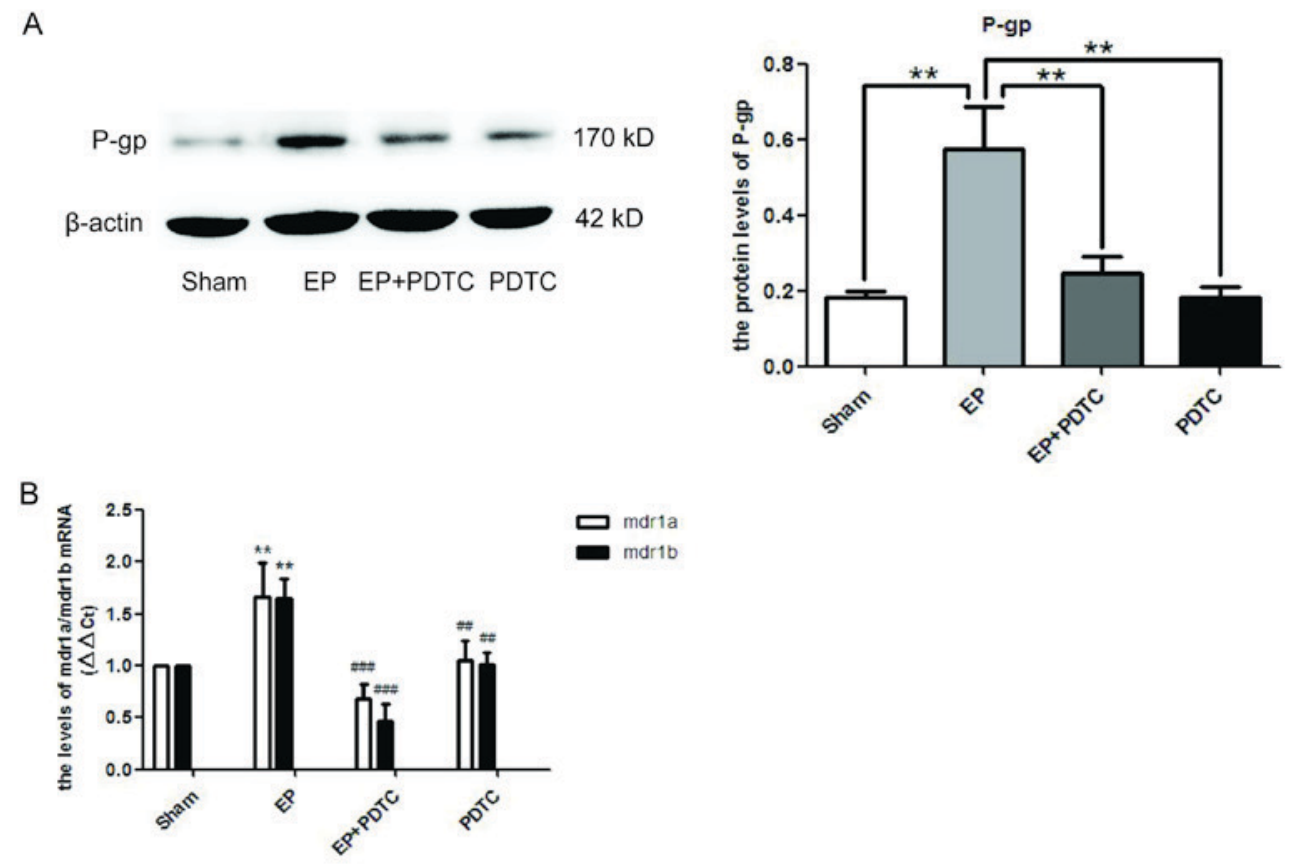

C
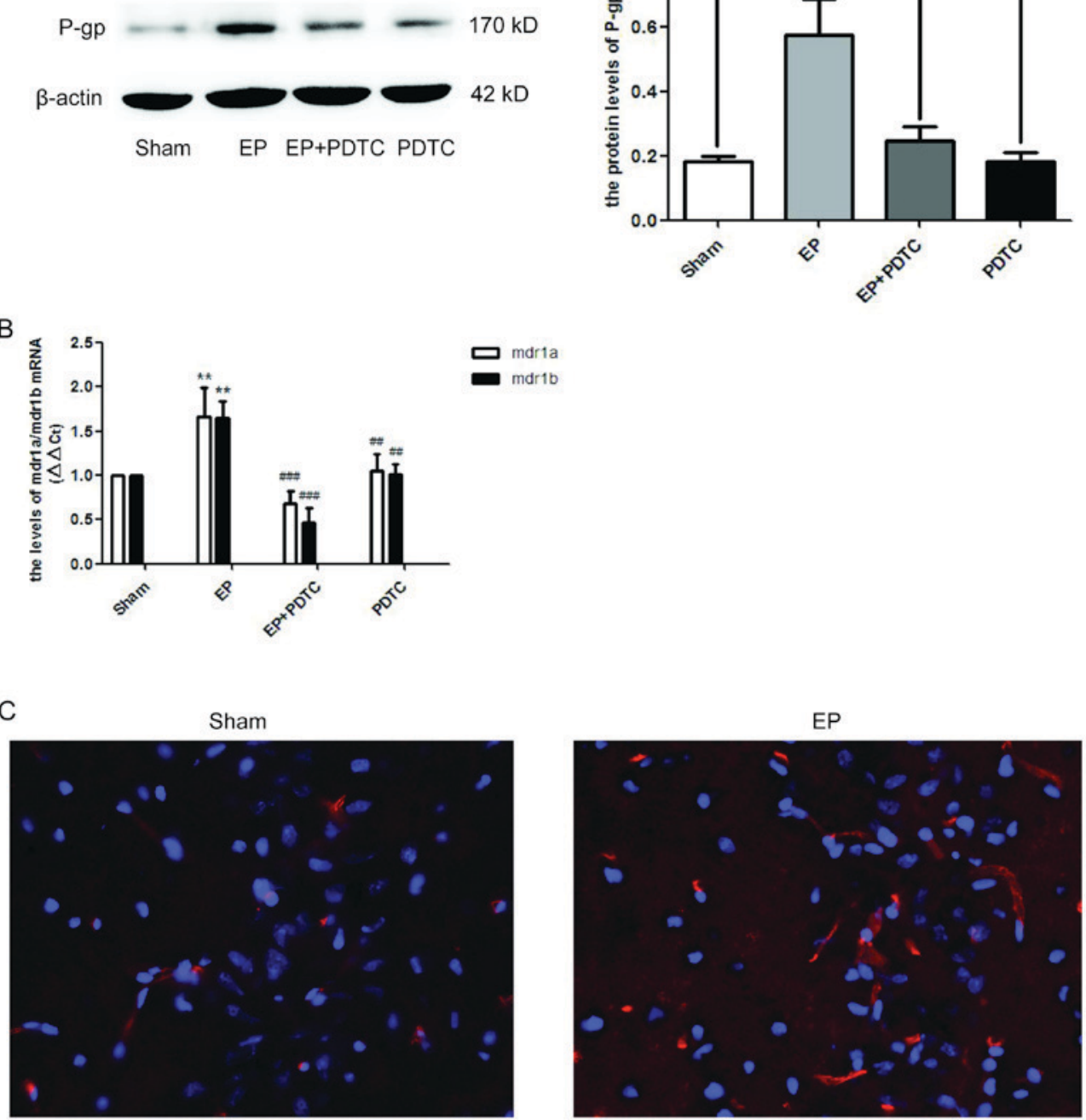

EP+PDTC
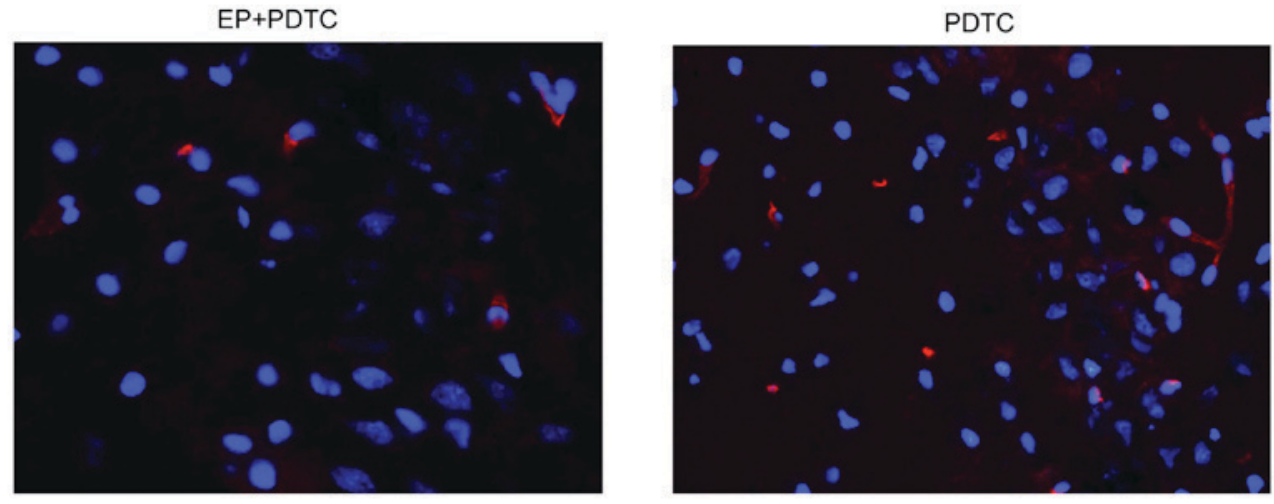

Figure 4. Inhibition of NF-kB by PDTC reduces the expression levels of P-gp in epileptic rat brains. (A) P-gp expression levels in each group were detected at $72 \mathrm{~h}$ following termination of status epilepticus by western blotting. Densitometry analysis was performed and data are presented as mean \pm standard deviation. PDTC significantly reduced the expression levels of P-gp in the EP + PDTC compared with the EP and Sham groups ( $\left({ }^{* *} \mathrm{P}<0.01\right)$. However, there was no statistical difference in expression between the EP + PDCT and PDTC groups. (B) mRNA expression levels of $M D R 1 A / B$ were significantly enhanced in the EP group compared with the sham group, and were significantly reduced in the $\mathrm{EP}+\mathrm{PDTC}$ compared with the PDTC group. $\left(\mathrm{P}<0.01 \mathrm{vs}\right.$. sham; ${ }^{\# \#} \mathrm{P}<0.01$ and

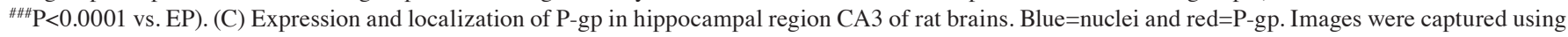
$\mathrm{x} 400$ magnification. Compared with the EP group, P-gp was reduced in the EP + PDTC group and was primarily localized to blood vessels. NF- $\mathrm{B}$, nuclear factor-кB; PDTC, pyrrolidinedithiocarbamic acid; P-gp, P-glycoprotein; EP, pilocarpine-induced epilepsy group.

glial-like cells in the rat dentate gyrus 1 week after seizures induced by electrical kindling. However, Guo et al (49) reported that $\mathrm{P}-\mathrm{gp}$ was not expressed in hippocampus neurons
4 weeks after pilocarpine-induced epilepsy in rats. During immunofluorescence testing, specific markers for the different cell types were not applied. This was a limitation of the present 
study, which could be resolved with specific markers for blood vessels and neurons in future studies.

In conclusion, the present study demonstrated that HMGB1 knockdown may reduce the expression levels of $M D R 1 A / B$ mRNA and P-gp protein via RAGE/NF- $\kappa$ B inflammatory signaling pathways. This may partly explain the underlying mechanism of P-gp overexpression in pilocarpine-induced SE rat brains. Therefore, targeting the HMGB1/RAGE/NF- $\kappa$ B signaling pathway may be a potential strategy for the treatment of DRE.

\section{Acknowledgements}

The present study was supported by the National Natural Science Foundation of China (grant no. 81171222). The authors would like to thank Dr Zhang Qiaoquan (Department of Neuropathology, Nanjing Brain Hospital, Jiangsu, China) for their assistance with the immunofluorescence.

\section{References}

1. Ngugi AK, Bottomley C, Kleinschmidt I, Sander JW and Newton CR: Estimation of the burden of active and life-time epilepsy: A meta-analytic approach. Epilepsia 51: 883-890, 2010.

2. Ni H, Sun Q, Tian T, Feng X and Sun BL: Long-term expression of metabolism-associated genes in the rat hippocampus following recurrent neonatal seizures and its regulation by melatonin. Mol Med Rep 12: 2727-2734, 2015.

3. Stepień KM, Tomaszewska J and Czuczwar SJ: The multidrug transporter P-glycoprotein in pharmacoresistance to antiepileptic drugs. Pharmacol Rep 64: 1011-1019, 2012.

4. Zhang CB, Kwan P, Zuo Z and Baum L: The transport of antiepileptic drugs by P-glycoprotein. Adv Drug Deliv Rev 64: 930-42, 2012.

5. Avemary J, Salvamoser JD, Peraud A, Rémi J, Noachtar S, Fricker G and Potschka H: Dynamic regulation of P-glycoprotein in human brain capillaries. Mol Pharm 10: 3333-3341, 2013.

6. Potschka $\mathrm{H}$ and Luna-Munguia $\mathrm{H}$ : CNS transporters and drug delivery in epilepsy. Curr Pharm Des 20: 1534-1542, 2014.

7. Bartels AL, de Klerk OL, Kortekaas R, de Vries JJ and Leenders KL: 11C-verapamil to assess P-gp function in human brain during aging, depression and neurodegenerative disease. Curr Top Med Chem 10: 1775-1784, 2010.

8. Holtman L, van Vliet EA, Edelbroek PM, Aronica E and Gorter JA: Cox-2 inhibition can lead to adverse effects in a rat model for temporal lobeepilepsy. Epilepsy Res 91: 49-56, 2010.

9. Hartz AM, Notenboom S and Bauer B: Signaling to P-glycoprotein-A new therapeutic target to treat drug-resistant epilepsy? Drug News Perspect 22: 393-397, 2009.

10. Vezzani A, French J, Bartfai T and Baram TZ: The role of inflammation in epilepsy. Nat Rev Neurol 7: 31-40, 2011.

11. Kawase A, Norikane S, Okada A, Adachi M, Kato Y and Iwaki M: Distinct alterations in ATP-Binding cassette transporter expression in liver, kidney, small intestine, and brain in adjuvant-induced arthritic rats. J Pharm Sci 103: 2556-2564, 2014.

12. Doorduin J, de Vries EF, Dierckx RA and Klein HC: P-glycoprotein activity in the blood-brain barrier is affected by virus-induced neuroinflammation and antipsychotic treatment. Neuropharmacology 85: 548-553, 2014.

13. Rojas A, Jiang JX, Ganesh T, Yang MS, Lelutiu N, Gueorguieva P and Dingledine R: Cyclooxygenase-2 in epilepsy. Epilepsia 55: 17-25, 2014.

14. Maroso M, Balosso S, Ravizza T, Liu J, Aronica E, Iyer AM, Rossetti C, Molteni M, Casalgrandi M, Manfredi AA, et al: Toll-like receptor 4 and high-mobility group box-1 are involved in ictogenesis and can be targeted to reduce seizures. Nat Med 16: 413-419, 2010

15. Chiavegato A, Zurolo E, Losi G, Aronica E and Carmignoto G: The inflammatory molecules IL-1 $\beta$ and HMGB1 can rapidly enhance focal seizure generation in a brain slice model of temporal lobe epilepsy. Front Cell Neurosci 8: 155, 2014.
16. Chen Y, Huang XJ, Yu N, Xie Y, Zhang K, Wen F, Liu H and Di Q: HMGB1 contributes to the expression of P-glycoprotein in mouse epileptic brain through Toll-like receptor 4 and receptor for advanced glycation end products. PLoS One 10: e0140918, 2015.

17. Iori V, MarosoM, Rizzi M, Iyer AM, Vertemara R, Carli M, Agresti A, Antonelli A, Bianchi ME, Aronica E, et al: Receptor for advanced glycation endproducts is upregulated in temporal lobe epilepsy and contributes to experimental seizures. Neurobiol Dis 58: 102-114, 2013.

18. Roberts DJ and Goralski KB: A critical overview of the influence of inflammation and infection on P-glycoprotein expression and activity in the brain. Expert Opin Drug Metab Toxicol 4: 1245-1264, 2008.

19. Yu N, Liu H, Zhang YF, Su LY, Liu XH, Li LC, Hao JB, Huang XJ and Di Q: Effects of brain IKK $\beta$ gene silencing by small interfering RNA on P-Glycoprotein expression and brain damage in the rat kainic acid-induced seizure model. CNS Neurol Disord Drug Targets 13: 661-672, 2014.

20. Angelo MF, Aguirre A, Avilés Reyes RX, Villarreal A, Lukin J, Melendez M, Vanasco V, Barker P, Alvarez S, Epstein A, et al: The proinflammatory RAGE/NF- $\kappa \mathrm{B}$ pathway is involved in neuronal damage and reactive gliosis in a model of sleep apnea by intermittent hypoxia. PLoS One 9: e107901, 2014.

21. Batkulwar KB, Bansode SB, Patil GV, Godbole RK, Kazi RS, Chinnathambi S, Shanmugam D and Kulkarni MJ: Investigation of phosphoproteome in RAGE signaling. Proteomics 15: 245-259, 2015.

22. Senn C, Hangartner C, Moes S, Guerini D and Hofbauer KG. Central administration of small interfering RNAs in rats: A comparison with antisenseoligonucleotides. Eur J Pharmacol 522: 30-37, 2005.

23. Sun $\mathrm{H}$, Wu H, Yu X, Zhang G, Zhang R, Zhan S, Wang H, Bu N, Ma X and Li Y: Angiotensin II and its receptor in activated microglia enhanced neuronal loss and cognitive impairment following pilocarpine-induced status epilepticus. Mol Cell Neurosci 65: 58-67, 2015.

24. Racine RJ: Modification of seizure activity by electrical stimulation. II. Motor seizure. Electroencephalogr Clin Neurophysiol 32: 281-294, 1972.

25. Lei C, Lin S, Zhang C, Tao W, Dong W, Hao Z, Liu M and Wu B: Activation of cerebral recovery by matrix metalloproteinase- 9 after intracerebral hemorrhage. Neuroscience 230: 86-93, 2013.

26. Soerensen J, Pekcec A, Fuest C, Nickel A and Potschka H: Pyrrolidine dithiocarbamate protects the piriform cortex in the pilocarpine status epilepticus model. Epilepsy Res 87: 177-183, 2009.

27. Livak KJ and Schmittgen TD: Analysis of relative gene expression data using real-time quantitative PCR and the 2(-Delta Delta C(T) Method. Methods 25: 402-408, 2001.

28. Liu C, Cui Z, Wang S and Zhang D: CD93 and GIPC expression and localization during central nervous system inflammation. Neural Regen Res 9: 1995-2001, 2014.

29. Turski WA, Cavalheiro EA, Schwarz M, Czuczwar SJ, Kleinrok Z and Turski L: Limbic seizures produced by pilocarpine in rats: Behavioural, eletroencephalographic and neuropathological study. Behav Brain Res 9: 315-335, 1983.

30. Choy M, Dubé CM, Patterson K, Barnes SR, Maras P, Blood AB, Hasso AN, Obenaus A and Baram TZ: A novel noninvasive predictive epilepsy biomarker with clinical potential. J Neurosci 34: 8672-8684, 2014.

31. Zanotto C, Abib RT, Batassini C, Tortorelli LS, Biasibetti R, Rodrigues L, Nardin P, Hansen F, Gottfried C, Leite MC and Gonçalves CA: Non-specific inhibitors of aquaporin-4 stimulate S100B secretion in acute hippocampal slices of rats. Brain Res 1491: 14-22, 2013

32. Kołosowska K, Maciejak P, Szyndler J, Turzyńska D, Sobolewska A and Płaźnik A: The role of interleukin-1 $\beta$ in the pentylenetetrazole-induced kindling of seizures, in the rat hippocampus. Eur J Pharmacol 731: 31-37, 2014.

33. Vezzani A: Epilepsy and inflammation in the brain: Overview and pathophysiology. Epilepsy Curr 14 (1 Suppl): S3-S7, 2014.

34. Yang H, Antoine DJ, Andersson U and Tracey KJ: The many faces of HMGB1: Molecular structure-functional activity in inflammation, apoptosis, and chemotaxis. J Leukoc Biol 93: 865-873, 2013.

35. Maroso M, Balosso S, Ravizza T, Liu J, Bianchi ME and Vezzani A: Interleukin-1 type 1 receptor/Toll-like receptor signalling in epilepsy: The importance of IL-1beta and high-mobility group box 1. J Intern Med 270: 319-326, 2011. 
36. Huebener P, Pradere JP, Hernandez C, Gwak GY, Caviglia JM, Mu X, Loike JD, Jenkins RE, Antoine DJ and Schwabe RF: The HMGB1/RAGE axis triggers neutrophil-mediated injury amplification following necrosis. J Clin Invest 125: 539-550, 2015.

37. Huang XJ, Hao JB, Di Q, Yu N, Zhang YF, Wen F and Chen Y: High mobility group protein $\mathrm{B} 1$ contributes to the expression of P-glycoprotein in hippocampus of epileptic rats. J Nanjing Med University (natural science) 8: 1029-1033, 2014.

38. Luo LD, Jin YC, Kim ID and Lee JK: Glycyrrhizin suppresses HMGB1 inductions in the hippocampus and subsequent accumulation in serum of a kainic acid-induced seizure mouse mode. Cell Mol Neurobiol 34: 987-997, 2014.

39. Wang H, Bloom O, Zhang M, Vishnubhakat JM, Ombrellino M, Che J, Frazier A, Yang H, Ivanova S, Borovikova L, et al: HMGB-1 as a late mediator of endotoxin lethality in mice. Science 285: 248-251, 1999.

40. Ibrahim ZA, Armour CL, Phipps S and Sukkar MB: RAGE and TLRs: Relatives, friends or neighbours? Mol Immunol 56 739-744, 2013

41. Xie J, Méndez JD, Méndez-Valenzuela V and Aguilar-Hernández MM: Cellular signalling of the receptor for advanced glycation end products (RAGE). Cell Signal 25: 2185-2197, 2013.

42. Mazarati A, Maroso M, Iori V, Vezzani A and Carli M: High-mobility group box-1 impairs memory in mice through both toll-like receptor 4 and Receptor for Advanced Glycation End Products. Exp Neurol 232: 143-148, 2011.
43. Dumitriu IE, Baruah P, Valentinis B, Voll RE, Herrmann M, Nawroth PP, Arnold B, Bianchi ME, Manfredi AA and Rovere-Querini P: Release of high mobility group box 1 by dendritic cells controls $\mathrm{T}$ cell activation via the receptor for advanced glycation end products. J Immunol 174: 7506-7515, 2005.

44. Kalea AZ, Reiniger N, Yang H, Arriero M, Schmidt AM and Hudson BI: Alternative splicing of the murine receptor for advanced glycation end-products (RAGE) gene. FASEB J 23: 1766-1774, 2009.

45. Bierhaus A, Humpert PM, Morcos M, Wendt T, Chavakis T, Arnold B, Stern DM and Nawroth PP: Understanding RAGE, the receptor for advanced glycation end products. J Mol Med (Berl) 83: 876-886, 2005.

46. Borst $\mathrm{P}$ and Schinkel AH: P-glycoprotein ABCB1: A major player in drug handling by mammals. J Clin Invest 123: 4131-4133, 2013.

47. Aronica E, Sisodiya SM and Gorter JA: Cerebral expression of drug transporters in epilepsy. Adv Drug Deliv Rev 64: 919-929, 2012.

48. van Vliet E, Aronica E, Redeker S, Marchi N, Rizzi M, Vezzani A and Gorter J: Selective and persistent upregulation of mdrlb mRNA and P-glycoprotein in the parahippocampal cortex of chronic epileptic rats. Epilepsy Res 60: 203-213, 2004.

49. Guo Y and Jiang L: Drug transporters are altered in brain, liver and kidney of rats with chronic epilepsy induced by lithium-pilocarpine. Neurol Res 32: 106-112, 2010. 